\title{
LEGALIZATION OF THE CRYPTO CURRENCY MARKET: OPPORTUNITIES AND RISKS FOR NATIONAL ECONOMIC SYSTEMS
}

Marat R. Safiullin ${ }^{1}$

Leonid A. Elshin ${ }^{2}$

Aliya A. Abdukaeva ${ }^{3}$

\begin{abstract}
Today there is a profound transformation of the traditional money and finance world. Innovations in the financial sector, new technologies, tools and systems entail serious and profound changes in the financial institutions that are familiar to us. One of the most important stages of these transformation processes was the emergence of crypto currencies, accompanied by the rapid development of related technologies and the lack of a clear picture of the future landscape of ecosystems. The search for scientifically grounded mechanisms that reveal the specific features of the impact of the crypto currency market legalization processes on national economic systems contributes significantly to an understanding and objective perception of the prospects for
\end{abstract}

their development. This paper is devoted to solving this problem. The object of the study is the global crypto currency market, which forms the institutional and conjunctural parameters of the national economic systems development. As the subject of the study is the process of designing and scientific and methodological justification of the prospects, opportunities and risks of the development of the national economy formed as a result of the legalization of the crypto currency market.As a result of the conducted studies and implemented assessments, scientifically grounded hypotheses on the influence of the "digital money" legalization mechanisms on key macroeconomic processes have been formed.

\footnotetext{
${ }^{1}$ Kazan Federal University.

${ }^{2}$ State Budgetary Institution Center of Perspective Economic Researches of the Academy of Sciences of the Republic of Tatarstan.e-mail:Leonid.Elshin@tatar.ru.Tel.:89872970679

${ }^{3}$ State Budgetary Institution Center of Perspective Economic Researches of the Academy of Sciences of the Republic of Tatarstan.e-mail: Leonid.Elshin@tatar.ru.Tel.:89872970679.
} 
Key words: crypto currency, national economic system, risks and opportunities, macroeconomic and social effects, legalization of the crypto currency market.

The paper was prepared within the framework of the RFBR-supported scientific project No. 18-010-00536

\section{Introduction}

A few years ago, most states took a stand of a passive "observer" for the development of the crypto currency market, but today its rapid development compels countries to develop a more definite position on this issue, balancing the support of innovative technologies and protecting the public from the risks associated with them. In general, Western economies mainly use the "soft touch" method monitoring the market and intervening when necessary. A fairly large number of countries have chosen the position of prohibitive measures with respect to crypto currency transactions. At the same time, government authorities of most countries understand the futility of impeding the development of this market, and are trying to determine their methods of regulating it and reducing the associated criminological risks [1].

However, development of effective regulatory measures in relation to crypto currencies is still at its early stage, primarily because of the very nature of this tool. With the assumption that crypto currencies operate on a global scale, they go beyond the responsibility of national institutions, while influencing the processes that are within the competence of these institutions. Today, national governments face the task of creating legal and regulatory framework that would take into account the risks associated with this market, but do not impede the introduction and development of innovations. A similar task is also faced by international institutions, including financial institutions, such as the International Monetary Fund, the World Bank and others [2].

The main advantages of crypto currencies are, first of all, reduction of transaction costs, speeding up transactions and their security, as well as data security through decentralization of transaction tracking and support tools, high anonymity and confidentiality, and lack of inflationary pressure [3]. 
Weak points are being studied by different experts, and their list is changing as the market develops; among the main ones are called such features as dependence on external network factors, extremely high volatility, cybersecurity issues, lack of lending, lack of regulatory institutions, and scalability problem.

The combination of presented strengths and weaknesses of "digital money" largely forms an ambiguous reaction to the legalization of crypto currency markets in the world.

Analysis of the approaches of countries to the regulation of crypto currency markets showed that there is no single position regarding the legal status of the digital money type under consideration in the world community today. There is also no single definition of the very concept of digital money, and, consequently, the instruments of their regulation vary in different countries and institutions within certain territorial boundaries. The only issue for which there is unanimity in the positions of the countries is the need to create a balanced regulatory and legal framework, identify measures and tools to prevent the use of crypto currency for criminal purposes [4].
The legal status of crypto currencies varies considerably in different countries. Many countries view the digital currency as a commodity or an investment asset. A number of countries recognized crypto currencies as a monetary unit (for example, Japan). In other countries, transactions with crypto currencies are prohibited for organizations, but are allowed for individuals.

To date, we can unequivocally state that in the world community a single (unified) approach to the legal regulation of crypto currency relations has not yet been worked out. At the same time, crypto currencies are considered by many world regulators as a promising tool in the monetary and credit policy of national economies.

\section{Methods}

In order to identify trends that demonstrate the attitude of countries to a crypto currency, and also to obtain a more detailed info of their legal status in different countries, an analysis was made reflecting the status of crypto currencies for each quarter from 2013 to 2017 in 29 countries. 
The following system of assessments of the legal status of crypto currencies was adopted as a basis:

-1 - negative attitude to crypto currencies / their complete ban;

0 - the status of crypto currencies is not defined;

0.5 - the question of legalization is being considered;

1 - recognized as private money, commodity, asset;

2 - legally recognized, taxed.

The results are shown in Figure 1, Table 1.

The realized analysis shows that in most states the legal status of crypto currencies is debatable and unsettled. At the same time, despite the heterogeneity of the attitude of national states to the crypto currency market the latter, judging from the data in Figure 1, shows a progressive positive trend, due to the growing trends of its legalization in various countries of the world (the average of the estimates for each quarter form a time series with a pronounced linear trend). This allows us to conclude that with each analyzed period, the level of confidence of the world community in crypto currencies is growing.

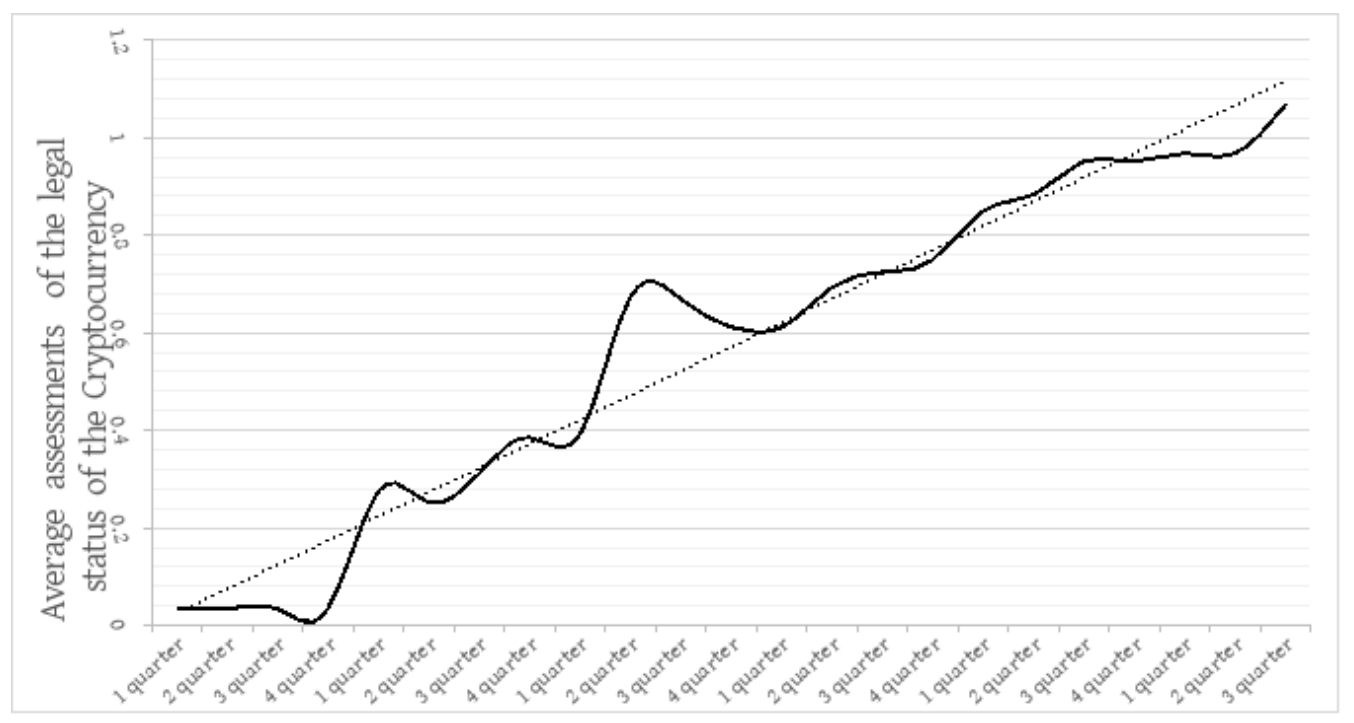

Figure 1- Average assessments of the legal status of crypto currencies 
Table 2- Analysis of the legal status of crypto currencies

\begin{tabular}{|c|c|c|c|c|c|c|c|c|c|c|c|c|c|c|c|c|c|c|c|}
\hline \multirow{2}{*}{ Country } & \multicolumn{4}{|c|}{2013} & \multicolumn{4}{|c|}{2014} & \multicolumn{4}{|c|}{2015} & \multicolumn{4}{|c|}{2016} & \multicolumn{3}{|c|}{2017} \\
\hline & Q1 & Q2 & Q3 & Q4 & Q1 & Q2 & Q3 & $\mathrm{Q} 4$ & Q1 & Q2 & Q3 & $\mathrm{Q} 4$ & Q1 & Q2 & Q3 & $\mathrm{Q} 4$ & Q1 & Q2 & $\overline{\mathrm{Q} 3}$ \\
\hline Russian & & & & & & & & & & & & & & & & & & & \\
\hline Federation & 0 & 0 & 0 & 0 & -1 & -1 & -1 & -1 & -1 & -1 & -1 & -1 & -1 & -1 & 0.5 & 0.5 & 0.5 & 0.5 & 0.5 \\
\hline Germany & 1 & 1 & 2 & 2 & 2 & 2 & 2 & 2 & 2 & 2 & 2 & 2 & 2 & 2 & 2 & 2 & 2 & 2 & 2 \\
\hline Croatia & 0 & 0.5 & 0.5 & 2 & 2 & 2 & 2 & 2 & 2 & 2 & 2 & 2 & 2 & 2 & 2 & 2 & 2 & 2 & 2 \\
\hline Sweden & 0 & 0.5 & 0.5 & 0.5 & 1 & 1 & 1 & 1 & 1 & 1 & 1 & 1 & 1 & 1 & 1 & 1 & 1 & 1 & 1 \\
\hline South Korea & 0 & 0 & 0.5 & 0.5 & 0.5 & 0.5 & 0.5 & 0.5 & 0.5 & 0.5 & 0.5 & 0.5 & 0.5 & 0.5 & 0.5 & 0.5 & 0.5 & 2 & 2 \\
\hline Thailand & 0 & 0 & -1 & -1 & 0 & 0 & 0 & 0 & 0 & 0 & 0 & 0 & 0 & 0 & 0 & 0 & 0 & 0 & 0 \\
\hline China & 1 & 1 & 1 & -1 & -1 & -1 & -1 & -1 & -1 & -1 & -1 & -1 & -1 & -1 & -1 & -1 & -1 & -1 & -1 \\
\hline USA & 0.5 & 0.5 & 0.5 & 1 & 1 & 1 & 1 & 1 & 1 & 1 & 1 & 1 & 1 & 1 & 1 & 1 & 1 & 1 & 1 \\
\hline Singapore & 0 & 0 & 0.5 & 0.5 & 1 & 1 & 1 & 1 & 1 & 1 & 1 & 1 & 1 & 1 & 1 & 1 & 1 & 1 & 1 \\
\hline Bulgaria & 0 & 0 & 0.5 & 0.5 & 0.5 & 2 & 2 & 2 & 2 & 2 & 2 & 2 & 2 & 2 & 2 & 2 & 2 & 2 & 2 \\
\hline Norway & 0 & 0 & 0 & 1 & 1 & 1 & 1 & 1 & 1 & 1 & 1 & 1 & 1 & 1 & 1 & 1 & 1 & 1 & 1 \\
\hline Ukraine & 0 & 0 & 0 & 0 & 0 & 0 & -1 & -1 & -1 & 1 & 1 & 1 & 1 & 1 & 1 & 1 & 1 & 1 & 1 \\
\hline France & 0 & 0 & 0 & -1 & -1 & -1 & 0.5 & 0.5 & 0.5 & 1 & 1 & 1 & 1 & 1 & 1 & 1 & 1 & 1 & 1 \\
\hline
\end{tabular}




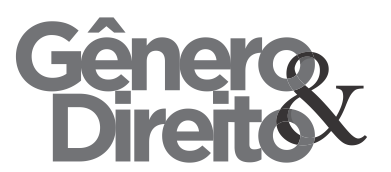

Periódico do Núcleo de Estudos e Pesquisas sobre Gênero e Direito

Centro de Ciências Jurídicas - Universidade Federal da Paraíba

V. 8 - No 04 - Ano 2019 - Special Edition

ISSN | 2179-7137 | http://periodicos.ufpb.br/ojs2/index.php/ged/index

397

Table 2, continued

\begin{tabular}{|c|c|c|c|c|c|c|c|c|c|c|c|c|c|c|c|c|c|c|c|}
\hline \multirow[t]{2}{*}{ Country } & \multicolumn{4}{|c|}{2013} & \multicolumn{4}{|c|}{2014} & \multicolumn{4}{|c|}{2015} & \multicolumn{4}{|c|}{2016} & \multicolumn{3}{|c|}{2017} \\
\hline & Q1 & Q2 & Q3 & $\mathrm{Q} 4$ & Q1 & Q2 & Q3 & $\mathrm{Q} 4$ & Q1 & Q2 & Q3 & Q4 & Q1 & Q2 & Q3 & Q4 & Q1 & Q2 & Q3 \\
\hline India & 1 & 1 & 1 & 1 & 1 & 1 & 1 & 1 & 1 & 1 & 1 & 1 & 1 & 1 & 1 & 1 & 1 & 1 & 1 \\
\hline Australia & & 1 & 1 & 1 & 1 & 1 & 1 & 1 & 1 & 1 & 1 & 1 & 1 & 1 & 1 & 1 & 1 & 1 & 2 \\
\hline Belgium & 0 & 0 & 0 & 0 & -1 & -1 & -1 & -1 & -1 & -1 & -1 & -1 & -1 & -1 & -1 & -1 & -1 & -1 & -1 \\
\hline Canada & 0 & -1 & -1 & -1 & -1 & 1 & 1 & 1 & 1 & 1 & 1 & 1 & 1 & 2 & 2 & 2 & 2 & 2 & 2 \\
\hline Cyprus & 1 & 1 & 1 & 1 & 1 & 1 & 1 & 1 & 1 & 1 & 1 & 1 & 1 & 1 & 1 & 1 & 1 & 1 & 1 \\
\hline Denmark & 0 & -1 & -1 & -1 & 1 & 1 & 1 & 1 & 1 & 1 & 1 & 1 & 1 & 1 & 1 & 1 & 1 & 1 & 1 \\
\hline Hong Kong & 0 & 0 & 0 & -1 & -1 & -1 & -1 & -1 & -1 & -1 & 0 & 0 & 0 & 0 & 0 & 0 & 0 & 0 & 0 \\
\hline Israel & 0.5 & 0.5 & 0.5 & 0.5 & 0.5 & 0.5 & 0.5 & 0.5 & 0.5 & 0.5 & 0.5 & 0.5 & 0.5 & 0.5 & 0.5 & 0.5 & 1 & 1 & 1 \\
\hline Japan & 0 & 0 & 0 & -1 & -1 & 0.5 & 0.5 & 0.5 & 0.5 & 0.5 & 0.5 & 0.5 & 2 & 2 & 2 & 2 & 2 & 2 & 2 \\
\hline New Zealand & 0 & 0 & 0 & 0 & 0 & 0 & 0 & 0 & 0 & 0 & 0 & 0 & 0 & 0 & 0 & 0 & -1 & -1 & -1 \\
\hline Slovenia & 0 & 0 & 0 & 0.5 & 0.5 & 0.5 & 0.5 & 0.5 & 0.5 & 0.5 & 0.5 & 0.5 & 0.5 & 0.5 & 0.5 & 0.5 & 0.5 & 0.5 & 0.5 \\
\hline Spain & 1 & 1 & 1 & 1 & 1 & 1 & 1 & 1 & 1 & 1 & 1 & 1 & 1 & 1 & 1 & 1 & 1 & 1 & 1 \\
\hline $\begin{array}{l}\text { United } \\
\text { Kingdom }\end{array}$ & 0 & 0 & 0 & 0 & 0 & 1 & 1 & 1 & 1 & 1 & 1 & 1 & 1 & 1 & 1 & 1 & 1 & 1 & 1 \\
\hline Bulgaria & 0 & 0 & 0 & 0.5 & 0.5 & 2 & 2 & 2 & 2 & 2 & 2 & 2 & 2 & 2 & 2 & 2 & 2 & 2 & 2 \\
\hline
\end{tabular}


At the current time, in the conditions of a legal vacuum in the sphere of regulation of the crypto currency market, it can be stated that the uncertainty of the legal status of the crypto currency does not prohibit its turnover on the territory of the Russian Federation. The emphasis of state bodies on the prohibition of the release of money surrogates is not accidental, however, the attribution of a crypto currency to the money surrogate is somewhat contrived, since there is no definition of a surrogate in Russian legislation. Therefore, it can be considered that crypto currencies are not a monetary surrogate, although transactions with them may carry problems related to potential involvement in the implementation of questionable transactions.

Since the embedded token (crypto currency) does not have a legal obligation inside it, it does not provide either legally significant right to the owner. Based on this, it can be considered that there is no legal protection of such assets, and the risk that the owner of the crypto currency carries is the loss of funds invested in this asset, is not subject to compensation.
Nevertheless, legal regulation for this kind of assets is required, since a crypto currency has its purchasing power and is involved in economic turnover, so already there are attempts in Russia and abroad to give it the status of a payment instrument, a financial asset, a commodity or a generic obligation.

\section{Results and discussion}

Crypto currency has become an integral part of the modern world and has a huge impact on the economies of countries and in order to understand the consequences of expanding this market it seems extremely appropriate and relevant to develop an appropriate methodological tool that would allow foreseeing the possible consequences and risks of legalizing "digital money" [5].

It should be noted that according to the P2P service for the exchange of bitcoins "LocalBitcoins", the average value of the weekly volume of transactions for the purchase and sale of bitcoins for the Russian ruble in 2017 was 603.32 million rubles. (Fig. 2) [6]. Upon that, the dynamics of its growth has an exponential character. The main sources of crypto currency generation in 
the Russian Federation are: mining and / or acquiring it at foreign cryptoexchanges. Thus, it can be argued that at the current time in Russia, the investment function of crypto currency does not exist due to the lack of tools to use it in the capacity of a payment / exchange mean in the sphere of trade. Legalization of a crypto currency through its legislative / regulatory consolidation in the legal field of the country opens the possibility of conducting commodity exchange transactions through the use of cryptotransactions, thereby creating significant effects of inflow of crypto currencies from abroad. This is especially relevant in the context of sanctions pressure on national economic systems, expressed, in particular, in restricting the access of foreign investment to sovereign state financial markets through the traditional institutions of their regulation (banking transactions). Taking into account the effects and known tools expressed in the possibility of converting crypto currency through exchange trades into traditional currency, the legalization of the market in question opens up broad possibilities for generating investment functions and the formation of appropriate macroeconomic and other effects. At the same time, an important aspect here is that the growth of investment activity as a result of the legalization of the crypto currency market will be formed, mainly, in non-primary sectors of the economy.

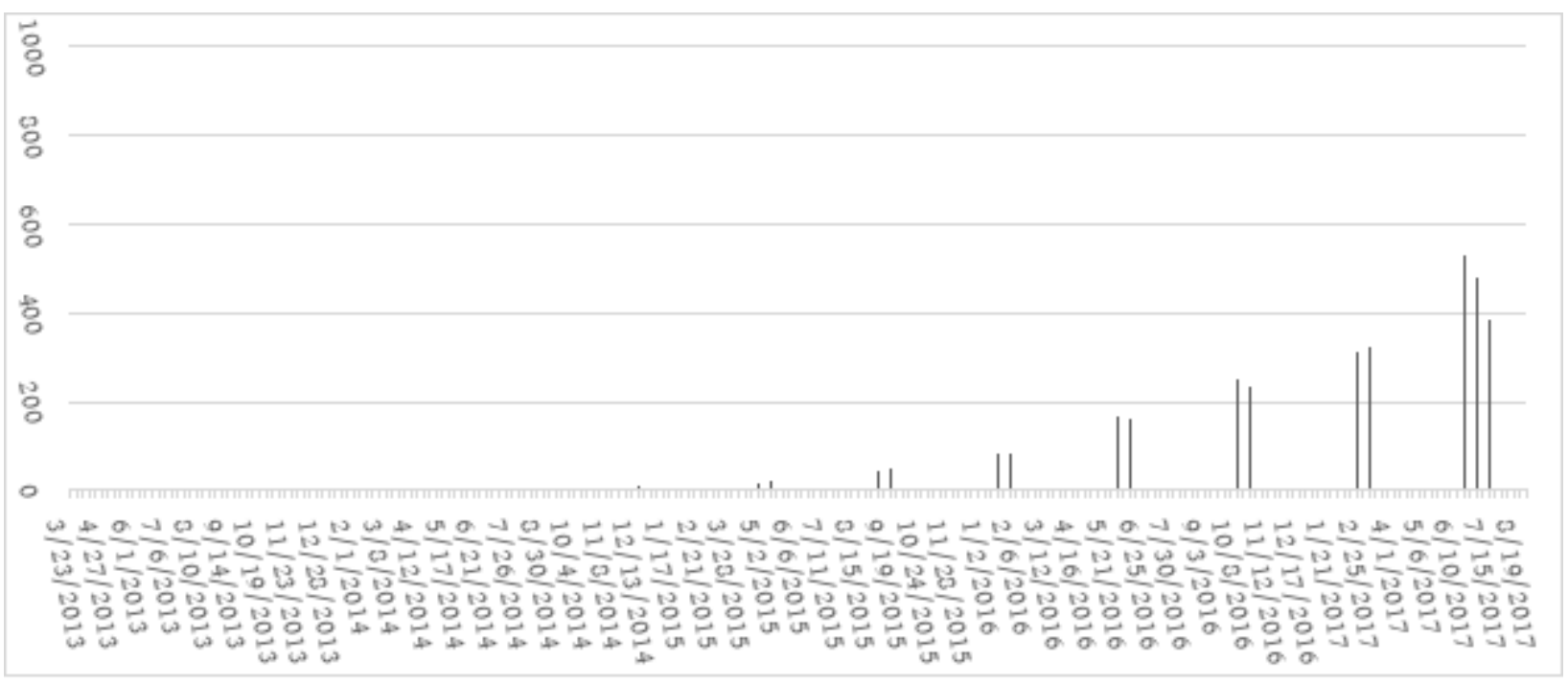

Figure 2 - Weekly turnover of Bitcoin in the Russian Federation, million rubles 


\section{Periódico do Núcleo de Estudos e Pesquisas sobre Gênero e Direito Centro de Ciências Jurídicas - Universidade Federal da Paraíba V. 8 - No 04 - Ano 2019 - Special Edition ISSN | 2179-7137 | http://periodicos.ufpb.br/ojs2/index.php/ged/index}

An important mechanism that forms positive macroeconomic effects due to the legalization of cryptology is the growth of economic activity of economic entities as a result of the fact that the crypto currency can serve as a driver opening new channels of exchange and consumption.

At the same time, despite the quite wide set of positive macroeconomic effects that are emerging as a result of legalization of the crypto currency market, risks may arise in parallel, primarily in reducing the financial stability of the banking and financial sectors of the national economy [7-8].

The growth of the crypto currency market increases pressure on monetary circulation which affects the national economy as a whole, accordingly. In this regard, it seems relevant to study the main directions that limit or, on the contrary, expand the range of regulation of financial markets and the development of the national payment system due to the integration of business processes into "crypto space". The expediency of this research is largely due to the fact that any violation of institutional reality based on traditional regulatory instruments may entail certain consequences, for example, expressed in violation of financial stability. Integration of the crypto currency market into the system of economic operations of the national economy is directly reflected in the balance sheet accounts of the Central Bank and other regulatory institutions. The main effect of the crypto currency market legalization process on the country's monetary system is generated as a result of the transformation of the money supply and, as a consequence, the monetary base [9].

In general, it can be said that legalization and active integration of the crypto currency market into economic circulation are capable of active pressure both on the payment system itself and on parameters for adjusting price indices in the economy by adjusting such factors as [10]:

1. Transformation of monetary aggregates due to the growth of the money circulation velocity.

2. Increase in cash that does not serve the commodity turnover.

It should be noted that at the current time, even despite the exponential growth of the global crypto 
currency market in recent years, many economists and statesmen assess its influence on macroeconomic and financial stability as insignificant. The basis of this approach is the extremely low volume of crypto market in the overall balance of the payment system. For example, in the Russian Federation, Bitcoin's weekly turnover is only $0.006 \%$ of cash and $0.001 \%$ of the money supply.

At the same time, in the foreseeable future, a scenario is likely, which is to include a further intensification of the market under investigation and its multi-structural integration into national economic systems, what makes it necessary to pay special attention to this issue today from the scientific and expert community. A significant contribution to the accelerated growth of the absolute values of the global crypto currency market can be made not only by its popularization as a progressive tool used in transactional and speculative operations, but also by the further growth of the exchange rate.

In all fairness, it should be noted that the high level of volatility of the exchange rate in the absolute majority of crypto currencies traded on crypto-
401

exchanges does not contribute to the current use of "digital money" as a means of commodity exchange operations. First of all, this is due to significant risks of financial stability of economic entities using crypto transactions, which are generated as a result of possible imbalance in the cost of cash flows due to significant exchange rate adjustments to the crypto currency.

\section{Summary}

It is necessary to emphasize separately in the capacity of key conclusions based on the allocated opportunities and risks of legalization of the crypto currency market, that negative scenarios for the development of macroeconomic trends of a negative nature are reduced to zero in conditions of low market development volumes corresponding to the current and medium-term perspective of $0.5-1.5$ billion rubles. In case of intensive growth of the crypto currency market in the Russian Federation, due to its legalization, appropriate prospects for generating threats and opportunities for the national economy and its residents are formed. In this connection, it is expedient to determine the measures of 
state regulation of the sphere in question.

So, summing up the presented reasoning, we can state that by now the regulation of the crypto currency market remains the subject of discussions, including at the state level, and the corresponding legal and regulatory framework has not been sufficiently developed, therefore each occurrence of crypto currency relations should be considered individually.

At the same time, by the present moment, issues that reveal the conceptual foundations of the digital currency (crypto currency) remain debatable in the scientific and expert community, beginning with the conceptual apparatus that reveals the essence and significance of the definition being studied, assigning a crypto currency to one or another category in the system of bookkeeping operations and financial accounting and up to legal and regulatory framework issues.

According to the results of the research conducted, it was established that in different countries of the world there are much differentiated approaches to understanding the essence of the digital currency and its role in a national economy. In some countries, crypto currencies are equaled to the monetary unit (Japan), in others they are treated as a derivative financial instrument, in the third as an intangible asset, in the fourth are completely banned due to the high risks of their use in the real economy.

\section{Conclusions}

The absence of a single conception and views on the concept, essence and role of digital currencies, and universal approaches to understanding its development mechanisms form a vacuum in the system of scientific and practical approaches to the regulation of the crypto currency market. At the same time, due to understanding that cryptoeconomics demonstrates the extremely dynamic growth rates in the world, expressed in multiple annual growth rates fixed in the last 2-3 years, the relevance of conducting the research aimed at development of scientifically sound regulatory and legal provisions in a single country is practically assured.

\section{Acknowledgements}

The work was carried out at the expense of the funds granted to Kazan State University for the performance of the 
state task in the sphere of scientific activity (No. 26.9776.2017 / BC)

\section{Bibliography}

Elshin L.A., Abdukaeva A.A., Prospects for generating business activity using digital money / Methods, mechanisms and factors of international competitiveness of national economies. 2017, p.91-94

Cocco L., Concas G., Marchesi M. Using an artificial financial market for studying a crypto currency market, Journal of Economic Interaction and Coordination - 2017. - Vol.12, Is.2. pp. 345-365.

Elshin L.A., Abdukaeva A.A., Financial instruments for energizing business activity: features and prospects / The problem of risk in the current crisis conditions of the world economy. 2017 , p.74-77.

Savelichev M.V. Determination of potential and perspective directions of introduction of corporate calculations based on electronic cryptographic
403

transactions / Electronic economic bulletin of Tatarstan. 2017, p.51-75

Draft Federal Law "On Digital Financial Assets"

URL: https://www.minfin.ru/ru/document/?id $\_4=121810 \&$ area_id $=4$ \& page_id $=$ $2104 \&$ popup $=$ Y\% 20\% 20\% 20\% 20\% $20 \#$

Service for statistical information on bitcoin

URL:

https://coin.dance/volume/localbitcoins/ $\underline{\mathrm{USB}}$

Hayes A. Crypto currency value formation: An empirical study leading to the cost of the production model for valuing bitcoin // Telematics and Informatics - 2017. - Vol.34, Is.7. - pp. 1308-1321.

Koblitz N. Menezes A.-J. Cryptocash, crypto currencies, and cryptocontracts // Designs, Codes and Cryptography 2016.- Vol.78, Is.1. - pp. 88-102.

Pieters G., Vivanco S. Financial regulations and price inconsistencies across the Bitcoin markets // Information 
Periódico do Núcleo de Estudos e Pesquisas sobre Gênero e Direito Centro de Ciências Jurídicas - Universidade Federal da Paraíba V. 8 - No 04 - Ano 2019 - Special Edition ISSN | 2179-7137 | http://periodicos.ufpb.br/ojs2/index.php/ged/index

Economics and Policy- 2017.- Vol.39.

pp. 1-14.

Sauer B. Virtual Currencies, the Money Market, and Monetary Policy. International Advances in Economic Research 2016. Vol.22, Is.2. - pp. 117130 